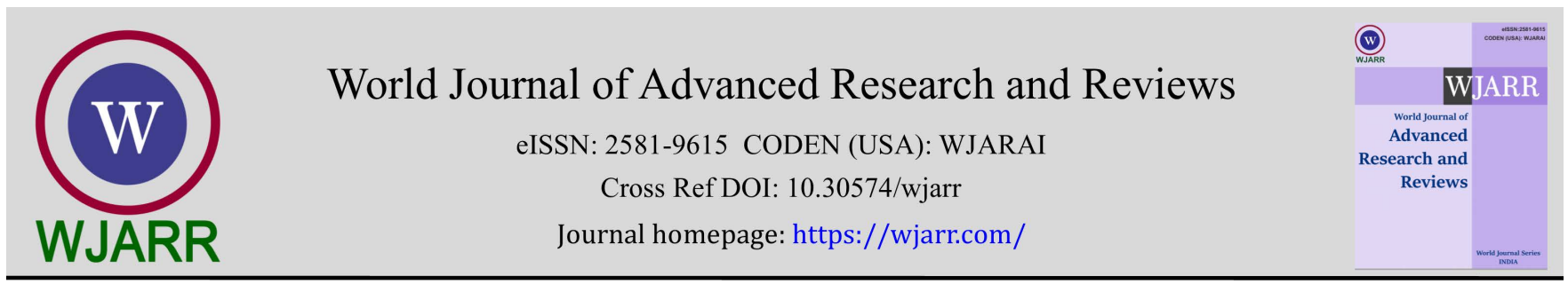

(REVIEW ARTICLE)

Check for updates

\title{
Theoretical consideration of solubility by Hildebrand solubility approach
}

\author{
Vaibhav Gulabrao Bhamare 1, *, Renuka Ravindra Joshi ${ }^{2}$, Mayur Sakharam Gangurde ${ }^{3}$ and Vijay V Pawar 3 \\ ${ }^{1}$ KKWES College of Pharmacy, Panchavati, Nashik, Maharashtra. \\ ${ }^{2}$ MGV's Institute of Pharmacy, Malegaon Camp Tal: Malegaon Dist: Nashik, Maharashtra. \\ ${ }^{3}$ SVS Institute of Pharmacy, Mungase, Tal: Malegaon Dist: Nashik, Maharashtra.
}

World Journal of Advanced Research and Reviews, 2021, 12(03), 528-541

Publication history: Received on 03 November 2021; revised on 12 December 2021; accepted on 14 December 2021

Article DOI: https://doi.org/10.30574/wjarr.2021.12.3.0680

\begin{abstract}
Pharmaceutical field is widely focusing on solubility parameter models to select solvent or non-solvent that can enhance solvency of drug. Solubility Parameter is very useful concept in understanding the mechanism of solvent and solvency behavior with their applications in pharmaceuticals to open the door of research having focus on theoretical considerations of solubility. Hildebrand and Hansen Solubility Parameter are frequently used to identify solvents.
\end{abstract}

Keywords: Solubility; Solvation; Hildebrand Solubility Parameter; Hansen solubility parameter

\section{Introduction}

Currently solubility study is on the peak point of formulation scientist and the basic reason is existence of nearly $70 \%$ drug in class II of BCS classification [1]. Solubility Parameter is very useful concept in understanding the mechanism of solvent. Hildebrand is the first one to coin the term solubility parameter [2,3]. The Solubility Parameter is a numerical figure which gives solvency behavior of specific solvent [4].

Various Solubility Parameter like Hildebrand Solubility, Hansen Solubility, Fedors, Van Krevelen are in use to depict the solvency behavior of solvent [5]. The Solubility Parameter, which expresses the cohesion between like molecules, is obtained from heat of vaporization, internal pressure, surface tension and other properties as expressed by Hildebrand and Scott [6]. Coating's pharmaceutical, cosmetics foodstuffs are produced as multi- component chemical mixture and Hildebrand solubility Parameter and Hansen solubility parameter plays vital role to meet environmental shelf life and product quality specifications of these compounds [7].

The solubility of drug is very important for pharmaceutical industry. Solubility means ability of solute to dissolve in a solvent especially water [8]. According IUPAC solubility is defined as ratio of designated solute in solvent [9]. Solubility plays major role in the manufacture of liquids orals as well as in the manufacturing of parenteral formulations, also it is important to obtain desired concentration of drug in systemic circulation for getting pharmacological response. The solubility of drugs in gastrointestinal fluids is an important step for absorption of drugs. Thus, solubility phenomenon is important in pharmacy $[10,11,12]$.

\section{Solution as a system}

A solution is a special type of homogeneous mixture composed of two or more substance. A Solvent is a substance that dissolves a solute resulting in a solution. The substance dissolved is called as the solute $[13,14,15,16]$. Solvents plays vital role like applying coatings, removing stains or adhesive. Choice of solvent mainly depend on factors such as

\footnotetext{
${ }^{*}$ Corresponding author: Vaibhav Gulabrao Bhamare

KKWES College of Pharmacy, Panchavati, Nashik, Maharashtra.

Copyright (C) 2021 Author(s) retain the copyright of this article. This article is published under the terms of the Creative Commons Attribution Liscense 4.0.
} 
evaporation rate, viscosity, environmental condition, health condition. And it is executed by the rule "like dissolves like" $[17,18,19]$.

\subsection{Ideal Solution}

The gas phase shows thermodynamic properties equivalent to the mixture of ideal gas [20]. The concept of the Ideal solutions describes limiting behavior of solution in similar way that the ideal gas explains the gases limiting behavior [21]. Ideal solution is equivalent to the perfect gases, but intermolecular attraction is not present in perfect gases [22]. In simple language ideal solution is a solution that for which each entity executes Raoult's law [23,24,25]. In Ideal solution solubility of solute does not depend on nature of solvent. There is no change in volume when components are mixed during mixture. The solute -solvent interactions are same as that of solute -solute and solvent- solvent interactions $[26,27,28]$.

\subsection{Non-Ideal Solution}

The Non-Ideal solution does not fallow Raoult's Law. This solution can occur when intermolecular forces between dissimilar molecules are greater than those between similar molecules and intermolecular forces between solute or solvent molecules are less strong than between molecules of similar (of the same type) molecules [29].

\section{Solubility Parameter}

Solubility Parameter is an intrinsic physicochemical property of substance. It expresses the cohesive forces between like molecules [30]. The simple definition of solubility parameter is as "a systematic description of the miscibility behavior of solvents" [31]. It is a square root of the cohesive energy density in which numerical value indicates the solvency behavior of a specific solvent and the represented by a delta $(\delta)$ [32]. It provides straightforward method of comparing and predicting cohesive and adhesive properties of materials [33]. It is useful for polymer, predicting the swelling of elastomers by solvents, determining solvent pressure in devolatilization and predicting polymer-binary, polymer-polymer solvent equilibrium, permeation rates of solvent, also, it is useful for characterizing the surface of fibers, pigments, fillers [34,35,36,37].

In case of polymer, Hildebrand Parameter cannot obtain from heat of vaporization because of their no volatility $[38,39,40]$. Therefore, it is obtained using atomic contribution group method or direct correlation method $[41,42,43]$.

Indirect methods namely consist of solvency testing, osmotic pressure, swelling values and specific volume [44]. Refractive index, H-bonding parameter, dielectric constant, surface tension these are the Correlation method [45]. Van Krevelen and Hoftyzer (VKH) method also used to determine the polymer and solvent volume. They are also known as atomic group contribution method [46,47]. Partial solubility of polymer can be calculated from VKH with the help of molar volume and molar attractions [48].

\section{Hildebrand solubility parameter}

Hildebrand solubility Parameter provides numerical value of the degree of interactions between materials [49,50,51]. It is a good sign of solubility mainly for non-polar material such as polymers. The entity of this method is Cohesive Energy Density [52].

Hildebrand Solubility is defined as "square root of Cohesive Energy Density" [53].

$$
\delta=\sqrt{\frac{\Delta \mathrm{Hv}-\mathrm{RT}}{\mathrm{Vm}}}
$$

Were,

Hv is the Heat of Vaporization

Vm is the Molar volume

$\mathrm{RT}$ is the Ideal gas 
Hildebrand Solubility is most widely applicable among all the systems which include Hildebrand number, hydrogen bonding value, fractional parameter and Hansen parameter [54]. Also, it is presented in the form of two- or threedimensional graph and a triangular graph known as a Teas graph. The Hildebrand Solubility Parameter is one of the oldest measures of solvent polarity. "Higher value of solubility parameter indicates greater solvent polarity" [55,56,57].

Hildebrand Solubility Parameter was first introduced by Joel H. Hildebrand and Scott (1936) in the article "The Solubility of Non-electrolytes" [58]. The numerical value that indicates relative solvency behavior of a specific solvent is known as Solubility Parameter. The said numerical value is derived from Cohesive Energy Density of the substance [59].

Heat of vaporization governs the basis for cohesive energy density $[60,61]$. The interdependence of solubility parameter on cohesive energy density and of cohesive energy density on heat of vaporization is clarified from relationship between heat of vaporization, Van der Waals force and solubility [62].

\subsection{Heat of vaporization}

Vaporization is a transitional phase, in which transition of molecules proceeds from a liquid/solid to a gaseous form [63]. Molecule on a surface is usually the first to undergo a phase change. Heat of Vaporization means amount of heat required to evaporate a liquid [64]. Direct conversion of solid to vapor is called as sublimation whereas the formation of vapor bubble within liquid is called as boiling [65].

There are two types of vaporization namely evaporation and boiling [66]. When liquid is heated to its boiling point, energy is added which separate the liquid into the gas and temperature increases. Added energy is used to break the bonds and separate the molecule of the liquid. Once all the bonds are broken into there is no use of further addition of heat [67].

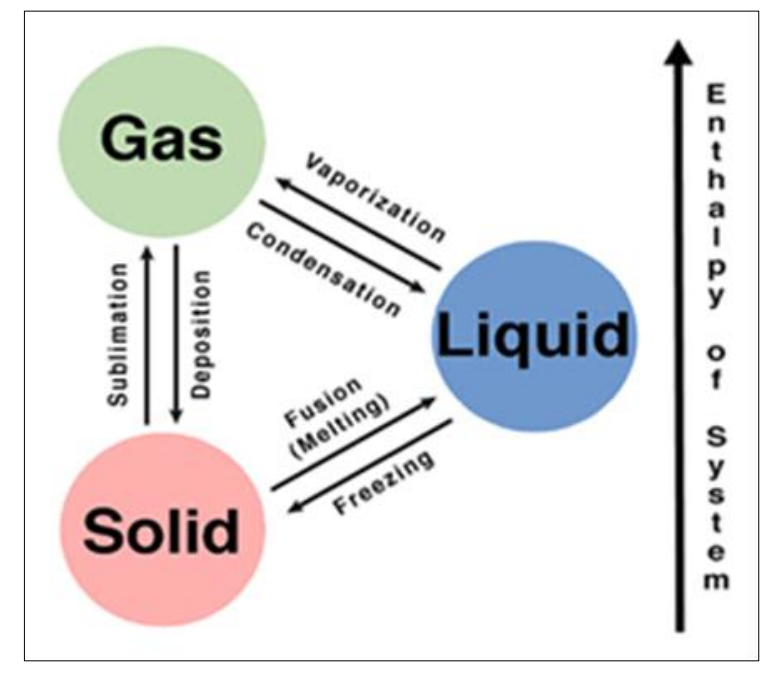

Figure 1 Enthalpy of System

If we measure the amount of energy, it gives amount of Van der Waals force that molecule of liquid carries together. The temperature at which liquid boils is not that much important in contrast of the amount of heat required for separation of the molecule [68]. Here, temperature at which liquid begins to boils is not essential, but the amount of heat required to separate the molecules plays important role [69]. A liquid having low boiling point required large amount of energy to vaporize, while liquid with high boiling point may vaporized rapidly, or vice versa [70].

Vaporization is an Endothermic process, hence $\mathrm{H}_{\mathrm{vap}}>0$ [71].

$$
\mathrm{H}_{\text {Vapor }}-\mathrm{H}_{\text {liquid }}=\mathrm{H}_{\mathrm{vap}}
$$

Where,

$\mathrm{H}_{\text {vap }}$ is the change in enthalpy 
$\mathrm{H}_{\text {vapor }}$ is the enthalpy of the gas state of compound

$\mathrm{H}_{\text {liquid }}$ is the enthalpy of the liquid state of compound

\subsection{Cohesive energy density}

Cohesive Energy Density is defined as energy needed to expel a molecule from its adjacent neighbors [72].

Cohesive Energy Density $=\frac{\Delta \mathrm{E}}{\mathrm{V}}$

Also, from heat of vaporization

$$
\mathrm{C}=\frac{\Delta \mathrm{Hv}-\mathrm{RT}}{\mathrm{Vm}}
$$

Where,

$\mathrm{C}$ is the cohesive energy density

$\mathrm{H}$ is the heat of vaporization

$\mathrm{R}$ is the gas constant

$\mathrm{T}$ is the temperature

$\mathrm{Vm}$ is the molar volume

In other quarters, the cohesive energy density is a numerical value that indicates the heat of vaporization in calories per cubic centimeter and it is related to the degree of Van der Waals forces [73].

Cohesive Energy density method are used to determine the group of pressure and temperature equilibrated structure it gives condensed phase properties, consisting Hildebrand and Hansen solubility behavior of polymer and solvent [74].

\subsection{Molecular attraction}

Intermolecular force creates interaction between molecules which contained force of attraction or repulsion [75]. This force acts in middle of molecules and atoms or ions. In a solution, the solvent molecules reduce this intermolecular adhesiveness in the solute and find their path between and around the molecule of solute. At the same time solvent molecules must be separated from each other by the molecules of solute. This can be done when attractions between molecules of both components are similar. If attraction is different, it results immiscibility [76,77].

\subsection{Van der Waals force}

Van der Waals Force defined as weak, short range electrostatic attractive force, present in between uncharged molecule and it is obtained from the interaction of transit or permanent electric dipole moments $[78,79,80]$. Sticky forces between molecules are called as Van der Waals force. Van der Waals forces occur due to electromagnetic interactions between molecules. It is a total Van der Waals force which is reflected in the simplest solubility value [81,82].

Examples of Van der Waals force are hydrogen bonding, dispersion forces and dipole-dipole interactions [83,84].

\subsection{Solvent Spectrum}

Solvent spectrum is obtained by ranking solvents according to solubility parameter, with solvents occupying positions near to other solvents of comparable strength $[85,86]$.

\subsection{Solvent Mixture}

It is an important parameter of Hildebrand solvent spectrum that the Hildebrand value of a solvent mixture can be determined by averaging the Hildebrand values of the individual solvents by volume $[87,88]$. For example, two parts of Toluene + one part of Acetone 


$$
(18.3 \times 2 / 3+19.7 \times 1 / 3)=18.7
$$

18.7 is the Hildebrand value which is same as chloroform

\subsection{Triangular Graph}

In triangular graph instead of two axes there are three axes oriented at $60^{\circ}$, and instead of three dimensions in space, the triangular graph is flat. On a triangular graph the zero point of any one scale is an upper limit of another one [89].

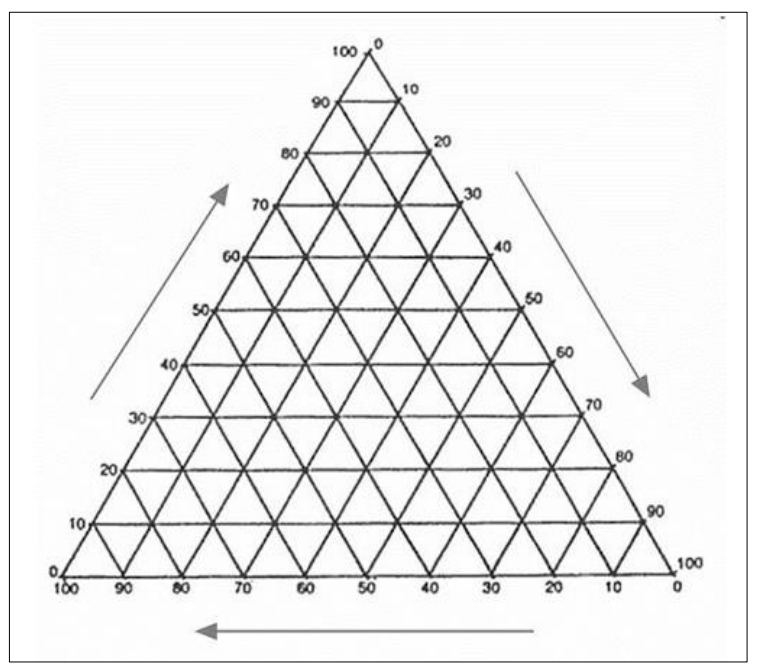

Figure 2 Triangular Graph

\subsection{Teas Graph}

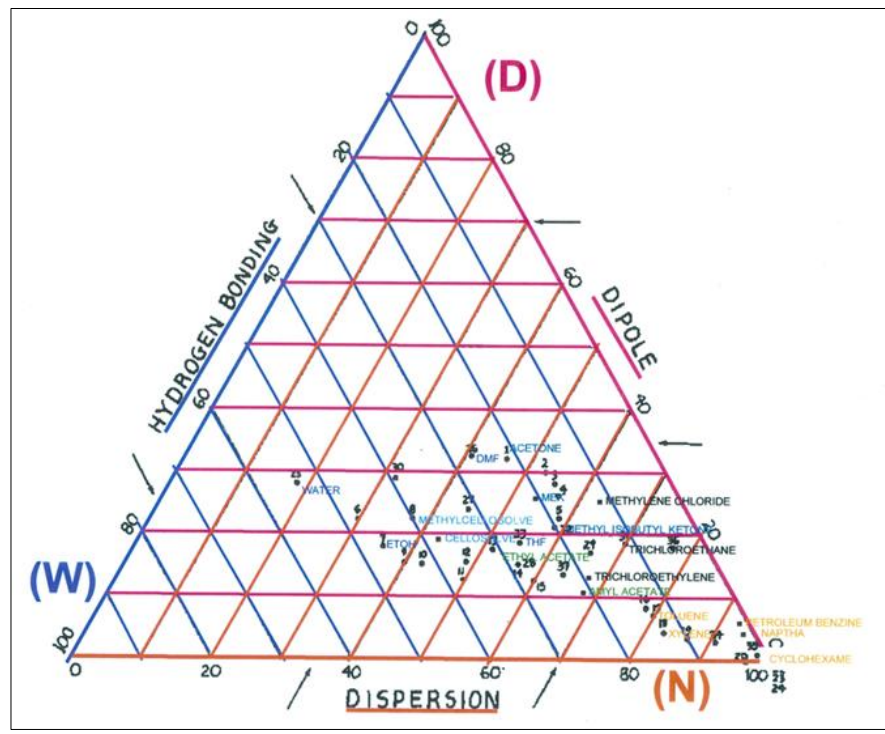

Figure 3 Teas Graph

The teas graph is known as a ternary fractional parameter solubility diagram. The teas graph is depended on the hypothetical presumption that all the component has the same Hildebrand value [90]. According this hypothesis the solubility behavior is determined, not by variation in total Hildebrand value, but the relative amount of three components forces (hydrogen bonding, dipole -dipole force and dispersion force [91]. 


\section{Hansen Solubility Parameter}

Determination of Hildebrand solubility parameter faces difficulty in case of substance with high boiling point. Hansen gives an extension of Hildebrand Solubility Method to determine relative miscibility of polar and hydrogen bonding system [92].

Based on the interaction between solute and solvent Charles M. Hansen distributes this Hildebrand solubility parameter into three components: Polar, Dispersion, and Hydrogen bonding thus, named as 3-D model or 3D solubility parameter $[93,94]$.

Dispersion force, Dipole-Dipole Force and Hydrogen Bonding are the three-dimensional solubility parameter [95,96]

It is given as,

$$
\mathrm{E}=\mathrm{Ed}+\mathrm{Ep}+\mathrm{Eh}
$$

The sum of the energy from dispersion (d), dipole-dipole(p), and hydrogen bonding (h) forces between molecules gives total Cohesive energy density(E) Dividing it by the molar volume gives the square of the total Hansen solubility parameter as the sum of the squares of the Hansen $\delta \mathrm{d}, \delta \mathrm{p}$ and $\delta \mathrm{h}[97]$.

$$
\begin{aligned}
& \frac{E}{V}=\frac{E_{d}}{V}+\frac{E_{p}}{V}+\frac{E_{h}}{V} \\
& \delta^{2}=\delta_{d}^{2}+\delta_{p}^{2}+\delta_{h}^{2}
\end{aligned}
$$

Where $\delta_{d}$, the energy from dispersion forces between molecules. $\delta_{p}$, the energy from dipole -dipole force between molecules. $\delta_{\mathrm{h}}$, the energy from hydrogen bonds in between molecules. $\delta$ value can be easily determined from heat of vaporization [98].

Hansen solubility parameter was first used in polymer and paint industry, now days it is also used in various industries like drug, cosmetic, oligomers. But results are not satisfactory in the case of polymer. There are two reasons, one is thermodynamic consideration and other is different functional group of drugs or cosmetic [99].

\subsection{Disperation Force}

The Dispersion force is the intermolecular force and impermanent attractive force that comes into existence when the electrons in two neighboring atoms occupies such a position that they form particular atoms which obtained from temporary dipoles [100,101]. Sometimes this attraction also called as London Dispersion force [102,103].

It is present in molecule, whether they are polar or non-polar. Larger molecules indicate stronger dispersion force than lighter molecule. This force is stronger between polarized molecules and weaker between the molecules that are not easily polarized [104].

\subsection{Dipole-Dipole force}

The positive end of one polar molecule is attracted towards negative end of another polar molecule with particular attractive forces known as Dipole-dipole force. They have vitality that range from 5kJ to 20kJ per mole [105]. It also called as Polar Forces. The polarity of molecule is related to its atomic composition its size and geometry [106]. Water and alcohol are strongly polar hexane is non polar and toluene is slightly polar. "Polar molecules organize themselves head to tail that means positive to negative and thus escalate in intermolecular attraction" [107].

\subsection{Hydrogen Bonding}

In hydrogen bonding electromagnetic attraction present between polar molecules in which hydrogen is attached to a larger atom, like carbon, oxygen or nitrogen. It is an attraction between the positive and negative poles of charged atoms [108]. 


\subsection{Three-Dimensional Hansen Space}

In three-dimensional Hansen space Dispersion force, Dipole-Dipole force and Hydrogen bonding can be treated as coordinates and closer molecules are more likely dissolved into each other. Interaction Radius ( $\left.\mathrm{R}_{0}\right)$ is used to determine the parameter of two molecules within range [109].

Solubility distance (Ra), which can be calculated for molecule combination (polymer-solvent combination), gives the region between solute and solvent in Hansen space. Once the polymer is clinched, then the distance between polymer and solvent can be calculated in Hansen Polymer are as fallow [110,111].

$$
\left(\mathrm{R}_{\mathrm{a}}\right)^{2}=\sqrt{4\left(\delta_{\mathrm{d} 2}-\delta_{\mathrm{d} 1}\right)^{2}+\left(\delta_{\mathrm{p} 2}-\delta_{\mathrm{p} 1}\right)^{2}+\left(\delta_{\mathrm{h} 2}-\delta_{\mathrm{h} 1}\right)^{2}}
$$

Dividing Solubility distance $\left(R_{a}\right)$ by the Interaction Radius $\left(R_{0}\right)$ gives Relative Energy Difference, which explain togetherness of polymer and solvent9 [112].

$$
\operatorname{RED}=\frac{\mathrm{R}_{\mathrm{a}}}{\mathrm{R}_{\mathrm{o}}}
$$

Condition: If the RED value will be less than 1 then solute and solvent are fully compatible to each other, estimated to be soluble. If the RED value 0 , then there is no any difference between solvent and polymer or solute and the polymer is predicted as soluble. If the RED value is higher than the 1 it shows lower affinities between solute and solvent. And if the RED is nearer to 1, this condition is called as Boundary condition [113].

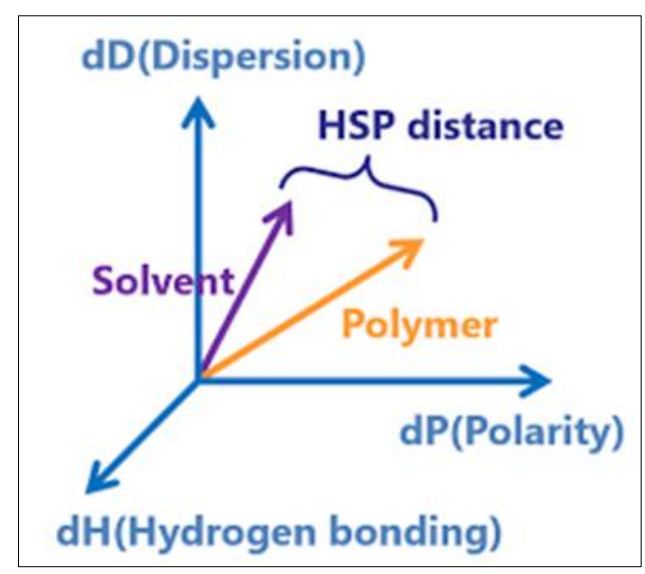

Figure 4 Three-Dimensional Hansen space

\subsection{Hildebrand Solubility and Solvation Process}

Solvation is the process of transferring a solute from some fixed point in an ideal gas phase, into a fixed point in the liquid [114]. It is the requirement of the solvation process that change in the Gibbs energy of the process be negative or zero. Solvation process will be thermodynamically selected only if the Gibbs energy of the solution is lessened, as compared to the Gibbs energy of solvent and solid or liquid or gas [115]. For the solvation process the Gibbs energy change splits into entropic components and enthalpic components $[116,117]$.

$$
\Delta \mathrm{G}_{\mathrm{M}}=\Delta \mathrm{H}_{\mathrm{M}}-\mathrm{T} \Delta \mathrm{S}_{\mathrm{M}}
$$

$\mathrm{G}_{M}$ is Gibb's energy of mixing, $\mathrm{H}_{M}$, is Enthalpy of mixing, $\mathrm{S}_{M}$ is Entropy of mixing. T is Temperature. Enthalpy of mixing can be expressed by, $[118,119]$

$$
\Delta \mathrm{H}_{\mathrm{M}}=\mathrm{V}_{\text {mix }}\left[\left(\frac{\Delta \mathrm{E}_{1}^{\mathrm{V}}}{\mathrm{V}_{1}}\right)^{1 / 2}-\left(\frac{\Delta \mathrm{E}_{2}^{\mathrm{V}}}{\mathrm{V}_{2}}\right)^{1 / 2}\right]^{2} \emptyset_{1} \emptyset_{2}
$$

Where, 
$\mathrm{V}_{\text {mix }}$ is the volume of mixture. $\mathrm{E}^{\mathrm{v}} 1$ is Vaporization energy of entity $\mathrm{I}, \mathrm{EV}_{2}$ is vaporization of energy of entity $\mathrm{II}, \mathrm{V}_{1}$ is molar volume of entity I, $\mathrm{V}_{2}$ is molar volume of entity II. $\emptyset_{1}$ is volume fraction of entity I, $\emptyset_{2}$ is volume fraction entity II [120].

\section{Extended Hildebrand Solubility Approach}

The Extended Hildebrand Solubility is modified version of the Scatchhard Hildebrand Equation. This parameter is used to calculate salvation of polar and non-polar solvents ranging from non-polar hydrocarbons to highly polar solvents like alcohols, glycols, water. It is applied to liquid - liquid systems [121,122].

\section{Units}

Hildebrand Values are shown in both, common form and newer form. In common form which is derived from cohesive energy densities (calories/cc) and a newer form means standard international units (SI) is derived from cohesive pressure. The SI unit for indicating pressure is Pascal and SI unit for indicating Hildebrand solubility parameter is MegaPascal $[123,124]$

SI Parameters are twice the value of standard parameters

$\delta / \mathrm{cal}^{1 / 2} \mathrm{~cm}^{-3 / 2}=0.48888 \times \delta / \mathrm{MPa}^{1 / 2}$

$\delta / \mathrm{MPa}^{1 / 2}=2.0455 \times \delta / \mathrm{cal}^{1 / 2} \mathrm{~cm}^{-3 / 2}$

\section{Standard Hildebrand values of solvent [125]}

Table 1 Standard Hildebrand values of solvent

\begin{tabular}{|l|c|c|}
\hline Solvent & $\Delta$ cal $\left.^{1 / 2} \mathbf{~ c m ~}^{-3 / 2}\right]$ & $\begin{array}{c}\Delta\left[\mathbf{M P a}^{\mathbf{1} / \mathbf{2}}\right] \\
\text { (SI unit) }\end{array}$ \\
\hline Diethyl ether & 7.62 & 15.4 \\
\hline Cyclohexane & 8.18 & 16.8 \\
\hline Carbon tetrachloride & 8.65 & 18.0 \\
\hline Ethyl acetate & 9.1 & 18.2 \\
\hline Toluene & 8.91 & 18.3 \\
\hline Benzene & 9.15 & 18.7 \\
\hline Chloroform & 9.21 & 18.7 \\
\hline Dichloromethane & 9.93 & 20.2 \\
\hline Acetone & 9.77 & 19.9 \\
\hline Ethylene dichloride & 9.76 & 20.2 \\
\hline Ethanol & 12.92 & 26.2 \\
\hline Dimethyl sulphoxide & 12.93 & 26.4 \\
\hline Methyl alcohol & 14.28 & 29.7 \\
\hline Propylene glycol & 14.80 & 30.7 \\
\hline Ethylene glycol & 16.30 & 34.9 \\
\hline Glycerol & 21.10 & 36.2 \\
\hline Water & 23.5 & 48.0 \\
\hline
\end{tabular}




\section{Advantages of Hildebrand Solubility Approach [126,127]}

- It gives simple predictions of phase equilibrium based on single parameter.

- It is also used in predicting solubility and swelling of polymers by solvents.

- It is useful for solvent and additives selection in formulation.

- Hildebrand solubility parameter of the solute is equivalent to Hildebrand Solubility Parameter of solvent.

\section{Limitations of Hildebrand Solubility Approach [128]}

- Important limitation of Hildebrand Solubility Parameter is that it is applied only to associated solutions (like dissolve like) or positive deviation from Raoult's Law.

- It is not applied to negative deviation from Raoult's Law which affect solvation or formation of electron donor acceptor complexes.

- It does not consider any specific interaction between molecules; therefore, three-dimensional Hansen solubility parameter are more practical in case of polymerization system.

- The Hildebrand solubility parameters will vary with temperature.

\section{Applications of Hildebrand Solubility Approach [129]}

- It can be applied in analytical chemistry, plasticizers, electrochemical sensors and catalysis.

- Extended Hildebrand Solubility Approach is used to determine the solubility of drug in binary solvents.

- It determines the maximum solubility in binary solvents like methanol-water. Solubility parameter, density, molar volumes were calculated and solubility was expressed in mole fraction.

- It is used to determine the solubility parameters of ionic liquids and Ionic-Liquid solvent mixtures from Intrinsic Viscosity.

- This study provides basic information on the solubility parameter of Ionic Liquids and mixture of Ionic liquid and solvents at different composition

- In molecular Dynamic with application to Electronic Nose Polymer Sensors.

- It is used in stable chemical formulation development.

- It is used by the industry for the determination of the permeation rate, mechanical properties and chemical resistance of polymer.

- It is used in the study and control of solvent -polymer behavior.

\section{Conclusion}

The numerical estimation of the degree of interaction between various materials signifies their solubility behavior. More closely the values, more likely solvation can take place. Thus the relative solvency behavior of a specific solvent can be a model to guide solvent selection.

\section{Compliance with ethical standards}

\section{Acknowledgments}

Authors are grateful to all researchers and reviewers for their valuable contribution in the field.

\section{Disclosure of conflict of interest}

No conflict of interest.

\section{References}

[1] Varshney HM, Chatterjee A. Solubility enhancement of poorly hydrophilic drugs by using different newer techniques: A Review. International journal of Therapeutic applications. 2012;6 (8): 13.

[2] Gedde UW, Hedenqvist MS. Fundamental polymer science. Cham: Springer. 20 Dec 2019.

[3] Schilling MR, Mazurek J, Learner TJ. Modern paints uncovered. In Proceedings from the Modern Paints Uncovered Symposium 2007. 
[4] Nema S, Ludwing JD, Parenteral Medication. CRC Press by Taylor and Francis Group. Boca Raton. $2019 ; 141$.

[5] Solubility Parameter. June 2011, Pirika.com/ENG/TCPE/SP-Theory.html ; access date April 2,2020.

[6] Nema S, Ludwing JD. Pharmaceutical dosage forms, Parental medications. Informa health care londone. 2010; 136.

[7] Belmares M, Blanco M, Goddard WA, Ross RB, Coldwell G, Chou SH, Pham J, Olofson PM, Thomas C. Hildebrand and Hansen Solubility Parameters from Molecular dynamic with applications to electronic nose polymer sensors, Wiley inter Science. 2004; 1814-1826.

[8] Singh MC, Sayyad AB, Sawant SD. Review on various techniques of solubility enhancement of poorly soluble drugs with special emphasis on solid dispersion. J Pharm Res. 2010 Oct; 3(10): 249-50.

[9] Savjani KT, Gajjar AK, Savjani JK. Drug solubility: Importance and Enhancement. International Scholarly Research Notices pharm. 2012; 1-10.

[10] Kumar S, Singh P. Various techniques for solubility enhancement: An overview. The Pharma Innovation. 2016; 5(1, Part A): 23.

[11] Ramesh V, Meenakshi S, Jyothirmayee N, Bullebbal M, Noorjahan SK, Rajeswari G, Nagesh Babu G, Madhavi D, Enhancement of solubility. Dissolution rate and Bioavailability of BCS Class II Drugs. International Journal of Ayurveda and Pharmaceutical Chemistry. 2016; 2: 80-95.

[12] Jain P, Goel A, Sharma S, Paramar M, Solubility Enhancement techniques with special emphasis on hydrotrophy. International Journal of pharmacy and Pharmaceutical Research. 2010; $1: 34-45$.

[13] Patel JN, Rathod DM, Patel NA, Moddsiva MK. Techniques to improve the solubility of poorly soluble drugs. International Journal of Pharmacy and life science. 2012; 3: 1459-1469.

[14] Patil MS, Godse SZ, Saudagar RB. Solubility enhancement by various techniques: An overview. World journal of pharmacy and pharmaceutical sciences. 2013; 2(6): 4558-72.

[15] Loftsson T. Aqueous solubility and true solutions. Die Pharmazie-An International Journal of Pharmaceutical Sciences. 1 Jun 2010; 65(6): 404-7.

[16] Chieh C. Inorganic Chemistry. Libretexts. 2019 June.

[17] Kirschenbaum LJ, Ruekberg BP. A correlation of the solubility of water in hydrocarbons as a function of temperature based on the corresponding vapor pressure of pure water.

[18] Ou S, Wang S, Zhou X, Chen L. Solubility behaviour of baicalin in polar and non-polar solvents: solubility parameters approach. Asian Journal of Chemistry. 2015; 27(7): 2401-5.

[19] Zhu J, Balieu R, Wang H. The use of solubility parameters and free energy theory for phase behaviour of polymermodified bitumen: a review. Road Materials and Pavement Design. 2019; 1-23.

[20] Atkins PW, De Paula J. Physical chemistry.

[21] Barton AF. Solubility parameters. Chemical Reviews. 1974; 75: 733.

[22] Zaslavsky BY. Aqueous two-phase partitioning. Physical chemistry and bioanalytical applications. 1995.

[23] Kugel RW. Raoult's Law: Binary Liquid-Vapor Phase Diagrams: A Simple Physical Chemistry Experiment. Journal of chemical education. 1998 Sep; 75(9): 1125.

[24] Tzias P, Treiner C, Chemla M. Applicability of Raoult's law in nonideal mixed solvents. Journal of Solution Chemistry. Jun 1977; 6(6): 393-402.

[25] Raoult's law, 2019 September.

[26] Smith PE, Mazo RM. On the theory of solute solubility in mixed solvents. The Journal of Physical Chemistry B. 3 Jul 2008; 112(26): 7875-84.

[27] Solutions; http://chemistry.bd.psu.edu/jircitano/solution.html ;access date April 8, 2020.

[28] Intermolecular Forces and the Solution Process. January 2016.

[29] Introduction to Non-ideal Solutions. June 2019.

[30] Han KH, Jeon GS, Hong IK, Lee SB. Prediction of solubility parameter from intrinsic viscosity. Journal of Industrial and Engineering Chemistry. 25 jul 2013; 19(4): 1130-6. 
[31] Hildebrand JH, Scott RL. Regular Solutions Prentice-Hall. Englewood Cliffs, NJ. 1962.

[32] Krevelen DW, Nijenhuis K. Properties of polymers: Their Correlation with chemical structure; Their numerical Estimation and predication From additive Group contributions Elsevier: Amsterdam. 2019; 189.

[33] Zeng W, Du Y, Xue, Frisch HL, Physical properties of polymer Handbook, Springer, New York. $1977 ; 289$.

[34] Miller-Chou BA, Koenig JL. A review of polymer dissolution. Progress in Polymer Science. 1 Aug 2003; 28(8): 1223-70.

[35] Hansen CM, Parameters HS, Handbook AU, Press CR. Boca Raton, FL. 2000.

[36] Grulke EA. Solubility parameter values. Polymer handbook. 1999.

[37] Bicerano J. Prediction of polymer properties. Marcel dekker. New York. 1993.

[38] Huang JC. Estimation of solubility parameter components of solutes and polymers using heat of vaporization and heat of sorption of solutes. Journal of applied polymer science. 15 May 2009; 112(4): 2027-32.

[39] Craver C, Carraher C. editors. Applied polymer science: 21st century. Elsevier. 19 Dec 2000.

[40] Nass LL, Heiberger CA. Encyclopedia of pve Revised and Expanded. Marcel Dekkar. New York. 1986:450.

[41] Code JE, Holder AJ, Eick JD. Direct and indirect quantum mechanical QSPR Hildebrand solubility parameter models. QSAR \& Combinatorial Science. 2008 Jul; 27(7): 841-9.

[42] Kitak T, Dumičić A, Planinšek O, Šibanc R, Srčič S. Determination of solubility parameters of ibuprofen and ibuprofen lysinate. Molecules. Dec 2015; 20(12): 21549-68.

[43] Gonzalez YM, De Caro P, Thiebaud-Roux S, Lacaze-Dufaure C. Fatty acid methyl esters as biosolvents of epoxy resins: a physicochemical study. Journal of solution chemistry. 2007 Apr; 36(4): 437-46.

[44] Fedors RF. A method for estimating both the solubility parameters and molar volumes of liquids. Polymer Engineering \& Science. 1974 Feb; 14(2): 147-54.

[45] Koenhen DM, Smolders CA. The determination of solubility parameters of solvents and polymers by means of correlations with other physical quantities. Journal of Applied Polymer Science. 1975 Apr; 19(4): 1163-79.

[46] Van Krevelen DW. Te Nijenhuis K. Properties of polymers: their correlation with chemical structure; their numerical estimation and prediction from additive group contributions. Elsevier. 1997.

[47] Bowden ST, Jones WJ. XXII. Latent heat of vaporization and composition. The London, Edinburgh, and Dublin Philosophical Magazine and Journal of Science. 1948 Feb 1; 39(289): 155-61.

[48] Özdemir C, Güner A. Solubility profiles of poly (ethylene glycol)/solvent systems, I: Qualitative comparison of solubility parameter approaches. European Polymer Journal. 1 Jul 2007; 43(7): 3068-93.

[49] Carvalho SP, Lucas EF, González G, Spinelli LS. Determining Hildebrand solubility parameter by ultraviolet spectroscopy and microcalorimetry. Journal of the Brazilian Chemical Society. 2013; 24: 1998-2007.

[50] Sanchez-Lengeling B, Roch LM, Perea JD, Langner S, Brabec CJ, Aspuru-Guzik A. A Bayesian approach to predict solubility parameters. Advanced Theory and Simulations. 2018: 1800069.

[51] Chen X, Yuan C, Wong CK, Zhang G. Molecular modeling of temperature dependence of solubility parameters for amorphous polymers. Journal of molecular modeling. 2012 Jun; 18(6): 2333-41.

[52] Lovelock KR. Quantifying intermolecular interactions of ionic liquids using cohesive energy densities. Royal Society open science. 6 Dec 2017; 4(12): 171223.

[53] Anderson BD. Predicting solubility/miscibility in amorphous dispersions: it is time to move beyond regular solution theories. Journal of pharmaceutical sciences. 1 Jan 2018; 107(1): 24-33.

[54] Wermuth CG. The practice of medicinal chemistry. Elsevier, USA 2008.

[55] Kanegsberg B, Kanegsberg E. editors. Handbook for critical cleaning: cleaning agents and systems. CRC press; 4 Apr 2011.

[56] Martin A, Wu PL, Liron Z, Cohen S. Dependence of solute solubility parameters on solvent polarity. Journal of pharmaceutical sciences. 1 Jun 1985; 74(6): 638-42.

[57] Weerachanchai P, wong Y, Lim KH, Than TT, Lee JM. Determination of solubility Parameters of ionic liquid and ionic liquid solvent Mixture from intrinsic viscosity, chemistry chem. 2014; 3580-3591. 
[58] Hildebrand JH, Scott RL. The solubility of nonelectrolytes. Reinhold Pub.Corp. New York, USA. 1950 ; 514.

[59] Goudarzi N, Chamjangali MA, Amin AH. Calculation of Hildebrand solubility parameters of some polymers using QSPR methods based on LS-SVM technique and theoretical molecular descriptors. Chinese Journal of Polymer Science. 2014 May; 32(5): 587-94.

[60] S howell MS. Handbook of detergent part D: Formulation. Surfactant science series. Taylor and francis Group. Boca Raton. 2006; 370.

[61] Broze G, editor. Handbook of Detergents, Part A: Properties. CRC Press. 14 Apr 1999.

[62] Pandey JD, Srivastava T, Chandra P, Rajput P, Dwivedi DK. Estimation of cohesive force energy of vaporization. Heat if vaporization cohesive energy density, solubility parameter and Van der Waals constant of binary liquid mixture using generalized hole theory. Indian J. Chem. 2007; 46A: 1605.

[63] Alibakhshi A. Enthalpy of vaporization, its temperature dependence and correlation with surface tension: a theoretical approach. Fluid Phase Equilibria. 2016; 1-19.

[64] Heat of vaporization. June 2015.

[65] Attinger D, Frankiewicz C, Betz AR, Schutzius TM, Ganguly R, Das A, Kim CJ, Megaridis CM. Surface engineering for phase change heat transfer: A review. MRS Energy \& Sustainability. 2014; 1.

[66] The Differences Between Vaporization \& Evaporation, March 2020; https://sciencing.com/differences-betweenvaporization-evaporation-12052824.html; access date April 17, 2020.

[67] Burke J. Solubility parameters: theory and application. The book and paper Group Annul. 1981.

[68] Burke J. Solubility parameters: theory and application. The book and paper Group Annul. 1984; 13-58.

[69] Phase Transitions: Melting, Boiling, and Subliming. 2020.

[70] Water's Heat of Vaporization. November 2019.

[71] Petrucci RH, Harwood WS, Herring FG, Madura JD. General chemistry: Principles \& modern applications, 9th Eds; 2007:474.

[72] Hildebrand JH. Solubility. III. Relative values of internal pressures and their practical application. Journal of the American Chemical Society. Jul 1919; 41(7): 1067-80.

[73] Saxena A, Katiyar S, Darunde D, Singh M. Solubility parameter - A review. Journal of Emerging Technology and Innovative Research. 2020; (7): 1558-1574.

[74] Rai N, Siepmann JI, Schultz NE, Ross RB. Pressure dependence of the Hildebrand solubility parameter and the internal pressure: Monte Carlo simulations for external pressures up to $300 \mathrm{MPa}$. The Journal of Physical Chemistry C. 1 Nov 2007; 111(43): 15634-41.

[75] Margenau H, Kestner NR. Theory of Intermolecular Forces: International Series of Monographs in Natural Philosophy. Elsevier. 1969.

[76] Al-Malah KI. Aqueous solubility of a simple (single-carbon) organic molecule as a function of its size \& dipole moment. Journal of molecular modeling. May 2011; 17(5): 1029-34.

[77] Tolls J, van Dijk J, Verbruggen EJ, Hermens JL, Loeprecht B, Schüürmann G. Aqueous solubility- molecular size relationships: A mechanistic case study using C10-to C19-alkanes. The Journal of Physical Chemistry A. 21 Mar 2002; 106(11): 2760-5.

[78] Leite FL, Bueno CC, Da Róz AL, Ziemath EC, Oliveira ON. Theoretical models for surface forces and adhesion and their measurement using atomic force microscopy. International journal of molecular sciences. Oct 2012; 13(10): 12773-856.

[79] French RH. Origins and applications of London dispersion forces and Hamaker constants in ceramics. Journal of the American Ceramic Society. Sep 2000; 83(9): 2117-46.

[80] Castellanos A. The relationship between attractive interparticle forces and bulk behaviour in dry and uncharged fine powders. Advances in physics. 1 Jun 2005; 54(4): 263-376.

[81] Hermann J, DiStasio Jr RA, Tkatchenko A. First-principles models for van der Waals interactions in molecules and materials: Concepts, theory, and applications. Chemical Reviews. 22 Mar 2017; 117(6): 4714-58. 
[82] Alastuey A, Cornu F, Martin PA. Van der Waals forces in presence of free charges: an exact derivation from equilibrium quantum correlations. The Journal of chemical physics. 7 Aug 2007; 127(5): 054506.

[83] Autumn K, Sitti M, Liang YA, Peattie AM, Hansen WR, Sponberg S, Kenny TW, Fearing R, Israelachvili JN, Full RJ. Evidence for van der Waals adhesion in gecko setae. Proceedings of the National Academy of Sciences. 17 Sep 2002; 99(19): 12252-6.

[84] Lifshitz EM, Hamermesh M. The theory of molecular attractive forces between solids. InPerspectives in Theoretical Physics. 1961; 153-176.

[85] Roegiers M, Zhmud B. Property blending relationships for binary mixtures of mineral oil and elektrionised vegetable oil: viscosity, solvent power, and seal compatibility index. Lubrication Science. Oct 2011; 23(6): 26378.

[86] Gogolewski S, inventor; Synthes USA LLC, assignee. Resorbable polymeric medical goods with improved mechanical properties and method for producing same. United States patent US 8,211,351. 2012.

[87] Kharwade M, Subrahmanyam CV, Kharwade P. INTERNATIONAL RESEARCH JOURNAL OF PHARMACY.

[88] OKAMURA KM, HIBI K, NAKAMURA H. A Calculation Method of Correspoding Mobile Phase Composition for Obtaining the Same Retention with Different Binary Organic/Aqueous Solvent Systems in Reversed Phase Liquid Chromatography. Analytical sciences. 10 Dec 1990; 6(6): 857-61.

[89] HildebrandSolubilityParameter. 2020.

[90] Teas JP. Graphic analysis of resin solubilities. Journal of paint technology. 1 Jan 1968; 40(516): 19-25.

[91] Benedek I. Pressure-sensitive formulation. CRC Press. 2000; 368.

[92] Small PA. Some factors affecting the solubility of polymers. Journal of Applied Chemistry. Feb 1953; 3(2): 71-80.

[93] Fukte SR, Wagh MP, Rawat S. Coformer selection: An important tool in cocrystal formation. Int J Pharm Pharm Sci. 2014; 6(7): 9-14.

[94] Süß S, Sobisch T, Peukert W, Lerche D, Segets D. Determination of Hansen parameters for particles: A standardized routine based on analytical centrifugation. Advanced Powder Technology. 1 Jul 2018; 29(7): 155061.

[95] Eichie FE, Okor RS, Groning R. Application of solubility parameters to the formulation of acrylate methacrylate film coating systems. Journal of applied polymer science. 22 Feb 2001; 87(8): 1339-44.

[96] Lan Y, Corradini MG, Liu X, May TE, Borondics F, Weiss RG, Rogers MA. Comparing and correlating solubility parameters governing the self-assembly of molecular gels using 1, 3: 2, 4-dibenzylidene sorbitol as the gelator. Langmuir. 2 Dec 2014; 30(47): 14128-42.

[97] Schoor Michael BV, Zlatev R. Scientific Health and Social Aspects of the Food industry. In Tech, Croatia. $2011 ; 465$.

[98] Stefanis E, Panayiotou C. Prediction of Hansen solubility parameters with a new group-contribution method. International Journal of Thermophysics. 1 Apr 2008; 29(2): 568-85.

[99] Louwerse MJ, Maldonado A, Rousseau S, Moreau-Masselon C, Roux B, Rothenberg G. Revisiting Hansen solubility parameters by including thermodynamics. ChemPhysChem. 3 Nov 2017; 18(21): 2999.

[100] Rantih NK, Mulyani S, Widhiyanti T. An analysis of multiple representation about intermolecular forces. InJournal of Physics: Conference Series. 1 Feb 2019; 1157(4): 042029.

[101] LondonDispersionForce. 2020.

[102] Gelardi G, Flatt RJ. Working mechanisms of water reducers and superplasticizers. InScience and technology of concrete admixtures. 1 Jan 2016; 257-278.

[103] Truhlar DG. Dispersion forces: neither fluctuating nor dispersing. Journal of Chemical Education. 18 Jul 2019 ; 96(8): 1671-5.

[104] Marcus Y. Solubility Parameter of Carbon Dioxide an Enigma. ACS omega. 17 Jan 2018; 3(1): 524-8.

[105] Dipole-Dipole Force. 2020.

[106] Hydrogen Bonding, Dipole-Dipole \& Ion-Dipole Forces: Strong Intermolecular Forces. 2020.

[107] Kumar DS. Herbal Bioactives and Food Fortification: Extraction and Formulation. CRC Press. 25 Sep 2015. 
[108] Wu S. Hansen solubility parameters as a quantifiable tool to study 12HSA self-assembly. Rutgers The State University of New Jersey-New Brunswick. 2014.

[109] Novo LP, Curvelo AA. Hansen solubility parameters: a tool for solvent selection for organosolv delignification. Industrial \& Engineering Chemistry Research. 1 Jul 2019; 58(31): 14520-7.

[110] Hansen CM. Hansen solubility parameters: a user's handbook. CRC press. 15 Jun 2007.

[111] Howell J, Roesing M, Boucher D. A functional approach to solubility parameter computations. The Journal of Physical Chemistry B. 27 Apr 2017; 121(16): 4191-201.

[112] Yu H, Hu J, Chang J. Selective separation of wood components based on Hansen's theory of solubility. Industrial \& engineering chemistry research. 15 Jun 2011; 50(12): 7513-9.

[113] Hansen CM. The three dimensional solubility parameter key to paint component affinities: I solvent, plasticizers, polymers and resins, J. paint technol. 1967; 39: 104-117.

[114] Ben-Naim A. Solvation and solubility of globular proteins. Pure and applied chemistry. 1 Jan 1997; 69(11): 223944.

[115] Baena Y, Barbosa H, Martínez F. Thermodynamic quantities of solvation and dilution for some acetanilide derivatives in octanol and water mutually saturateds. Eclética Química. Dce 2008; 33(4): 33-40.

[116] Schauperl M, Podewitz M, Waldner BJ, Liedl KR. Enthalpic and entropic contributions to hydrophobicity. Journal of chemical theory and computation. 13 Sep 2016; 12(9): 4600-10.

[117] Ben-Naim A. Molecular Theory of Water and Aqueous Solutions-Part 1: Understanding Water. World Scientific. 2011; 92.

[118] Kleppa OJ. Aspects of the thermodynamics of metallic solutions. J. Phys. Radium. 1962; 23(10): 763-72.

[119] Maniruzzaman M, Snowden MJ, Bradely MS, Douroumis D. Studies of intermolecular interactions in solid dispersions using advanced surface chemical analysis. RSC advances. 2 Sep 2015; 5(91): 74212-9.

[120] Bashimam M. Hansen solubility parameters: a quick review in pharmaceutical aspect. J Chem Pharm Res. 2015; 7: 597-9.

[121] Rathi PB, Mourya VK. Extended Hildebrand solubility approach: Satranidazole in mixtures of dioxane and water. Indian journal of pharmaceutical sciences. May 2011; 73(3): 315.

[122] Liu R. Water-insoluble drug formulation. CRC press. 2018; 17.

[123] Vandenburg HJ, Clifford AA, Bartle KD, Carlson RE, Carroll J, Newton ID. A simple solvent selection method for accelerated solvent extraction of additives from polymers. Analyst. 1999; 24(11): 1707-10.

[124] Jankovic S, Tsakiridou G, Ditzinger F, Koehl NJ, Price DJ, Ilie AR, Kalantzi L, Kimpe K, Holm R, Nair A, Griffin B. Application of the solubility parameter concept to assist with oral delivery of poorly water-soluble drugs-a PEARRL review. Journal of Pharmacy and Pharmacology. 2018; 1-23.

[125] Hildebrand solubility parameter. May 2008.

[126] Venkatram S, Kim C, Chandrasekaran A, Ramprasad R. Critical assessment of the hildebrand and hansen solubility parameters for polymers. Journal of chemical information and modeling. 23 sep 2019; 59(10): 4188-94.

[127] Hancock BC, York P, Rowe RC. The use of solubility parameters in pharmaceutical dosage form design. International journal of pharmaceutics. 14 Mar 1997; 148(1): 1-21.

[128] Abbott S, Hansen CM. Hansen solubility parameters in practice. Hansen-Solubility. 2008.

[129] Kushagra CK, Raghvendra D. Prediction of solubility of etodolac in binary solvents using extended Hildebrand solubility approach. American Journal of Life Science Researches. 8 Aug 2017; 5(3): 70-8. 